\title{
Joaquim Manoel de Macedo e educação: um projeto de civilização nos trópicos
}

\author{
Joaquim Manoel de Macedo and education: a civilization project in the tropics
}

\author{
Adjovanes Thadeu Silva de Almeida \\ Professor do Colégio Pedro II \\ adjovanes@hotmail.com
}

Resumo: O presente texto pretende estudar a contribuição do Instituto Histórico e Geográfico Brasileiro (IHGB) ao estabelecimento do que seria uma nação civilizada, de acordo com os padrões culturais fixados durante o Oitocentos. Para tanto, abordaremos o conceito de civilização, tal como entendido no Brasil no século XIX, e a trajetória de Joaquim Manuel de Macedo, um dos intelectuais que, tanto nos quadros do IHGB e em sua Revista como no âmbito do Colégio Pedro II, se encarregou de produzir uma obra com finalidades pedagógicas, procurando educar as futuras gerações de brasileiros.

Palavras Chaves: Instituto Histórico e Geográfico Brasileiro, Joaquim Manuel de Macedo, Educação.

\begin{abstract}
This paper aims to analyze the contribution of the Instituto Histórico e Biográfico Brasileiro (IHGB) for the establishment of what should be a civilized nation, according to the cultural standards set in the nineteenth century. For this purpose, we discuss the concept of civilization, as understood in Brazil during the nineteenth century, and the career of Joaquim Manuel de Macedo, one of the intellectuals who, both in IHGB and its magazine, as in the Colégio Pedro II, took the task of producing a work for educational purposes, seeking to educate future generations of Brazilians.

Keywords: Instituto Histórico e Geográfico Brasileiro, Joaquim Manuel de Macedo, Education.
\end{abstract}


Toda e qualquer sociedade produz artefatos culturais que fornecem sentido à vida (quer individual, quer coletiva). Tal ação constitui o "poder criador" da organização social, que se autoinstitui não apenas no aspecto material, mas, também, no que se refere ao simbólico. Com efeito, este imaginário assumiu diversas formas ao longo da trajetória histórica, por exemplo, religião, partidos políticos, legislação, moral, literatura, entre outros. Cornelius Castoriadis afirma que este imaginário primeiro ("radical”, em sua terminologia) encontra-se na base da produção cultural das várias sociedades, com seus produtos alterando-se em função das conjunturas específicas vivenciadas por cada uma (1982: 414).

A produção historiográfica do Instituto Histórico e Geográfico Brasileiro (IHGB) corroborava semelhante afirmação, uma vez que conseguimos, hodiernamente, identificar tais grupos e inferir-lhes as intenções. Ora, o imaginário se constitui uma produção coletiva que impossibilita a própria identificação de autoria. Porém, isso não impediu que tal intento fosse formulado, através do IHGB, em busca de dois objetivos principais: a valorização da civilização e da ação dos sujeitos que integram os grupos 78 governantes.

A historiografia produzida nos quadros do IHGB enfatizava a preponderância dos grandes homens, subtraindo os conflitos sociais que aparecem em qualquer conjuntura. A historiografia do IHGB exemplifica a participação da ideologia no imaginário, e se apropria de alguns aspectos parciais dessa produção simbólica, objetivando gerar mensagens que favoreçam seus adeptos e, ao mesmo tempo, desqualifiquem seus adversários na disputa pelo comando da sociedade.

No discurso produzido ao longo do século XIX, a ideia de civilização possuía lugar de destaque. Segundo o Dicionário da Língua Portuguesa, "CIVILIZAÇÃO, s.f. O ato de civilizar: o estado do povo civilizado" (SILVA, 1858, 1877). A civilização resultaria de uma ação intencional, que objetivaria, portanto, atingir determinada finalidade: produzir uma realidade social onde o refinamento ocupe o espaço até então dominado por comportamentos primitivos, como pode ser observado nos verbetes associados ao termo civilização:

CIVILIDADE, s. f. (do Lat. 'civilitas') ant. Ação de homem do povo, de mecânico, vil. 'Albig.' 'sofrer civilidade' i. é, vilanias. § Hoje se diz (e é 
melhor) 'civeldade'; porque 'civilidade significa hoje só 'cortesia', 'urbanidade', 'modo atencioso'; opp. a 'rusticidade', 'grosseria'.

(Civilidade, Polidez, Delicadeza, sin.) ‘Civilidade’ é propriamente uma disposição habitual, que nos faz evitar no comércio da vida, e no trato com os homens, tudo o que pode ofendê-los, ou desagradar lhes. A 'polidez' acrescenta à 'civilidade' o cuidado que pomos em agradar e obrigar os outros, e não só remove do trato e comércio dos homens todo o gênero de aspereza, e todas as maneiras inoficiosas, senão que se empenha em fazer cousas que sejam agradáveis, e deem gosto ás pessoas, com quem se trata. A 'delicadeza' supõe demais um tato fino, e uma certa penetração, que nos faz quase adivinhar os desejos, e até os pensamentos dos outros, para prevenirmos, quanto nos é possível os meios de os satisfazer, e comprazer.

Civilizado, p. p. de Civilizar.

$\S$ (Civilisado [ou Civilizado], Policiado, Polido. Sin.) Civilizado diz se de um povo, quando tendo deixado os costumes bárbaros se governa por leis. 'Policiado' quando pela obediência às leis tem adquirido o habito das virtudes sociais. E 'polido' quando em suas ações mostra elegância, urbanidade e gosto. A civilização estabelece se pelas leis que formam os bons costumes. E estes aperfeiçoam as leis, e policiam os povos. A polidez segue se depois.

CIVILIZADOR, A, adj. e s. Que civiliza, ilustra, promove a instrução, e pule os costumes de um povo.

CIVILIZAR, v. a. Fazer civil o povo, a nação, os costumes; ilustrá-lo, dar lhe instrução. §. + it. diz-se Propagar a civilidade. §. + Muitos escrevem 'civilizar' e os der.

CIVIL, pl. 'Civís', adj. 2 g. (do Lat. 'Civilis', de 'Civis', cidadão). Que pertence à cidade, ou sociedade de homens, que vivem debaixo de certas leis; e em negócios seculares: [...] (SILVA, 1858, 1877, v. 1: 471).

Desta maneira, civilizar acarretaria não apenas polir os costumes, mas, também, difundir o conhecimento e disciplinar as ações (vocabulário, por exemplo). No ideário oitocentista, muitas vezes esse objetivo deveria ser levado à efeito pelo Estado e seus dirigentes, que, assim, educariam os demais estratos sociais. Ao se produzir uma História oficial que tornasse inteligível o passado comum, estaria se educando a coletividade e, assim, auxiliando na empreitada civilizatória, ao tornar aquela trajetória passível de ser ensinada e aprendida, pois seria dotada de algum sentido. Tais funções foram assumidas pelo Instituto Histórico e Geográfico Brasileiro desde a sua fundação, e 
por seus intelectuais, muitos dos quais exerceram a profissão docente no Colégio Pedro II, como, por exemplo, Joaquim Manuel de Macedo, cujas ações serão analisadas nas páginas a seguir, e, em especial, através de um livro, $O$ ano biográfico brasileiro (1876).

\section{IHGB: 0 espaço produtor da história pátria}

Em 1838, um grupo de integrantes da Sociedade Auxiliadora da Indústria Nacional, sob a liderança do cônego Januário da Cunha Barbosa e do marechal Raymundo José da Cunha Mattos, fundou o Instituto Histórico e Geográfico Brasileiro. Sua criação fez parte da luta política então em curso, visto que os fundadores do Instituto haviam sido afastados das posições de mando do governo regencial a partir de 1837 (GUIMARÃES, 1995: 56).

Por outro lado, podemos perceber a criação do IHGB através de sua inserção no projeto para a construção de um passado para a jovem nação. O papel do Instituto Histórico consistia na elaboração da história nacional, processo por meio do qual se instituiriam mitos de origem e pais fundadores, realizando-se o amálgama de acontecimentos e personagens até então desconexos entre si, transformando-os em uma totalidade lógica e coerente, que fornecesse a identidade nacional.

Manoel Luís Salgado Guimarães buscou relacionar a gênese do IHGB à formação do Estado brasileiro, onde aquele produziria a interpretação canônica a respeito dos acontecimentos pretéritos, legitimando assim a atuação política dos grupos dirigentes (GUIMARÃES, 1988: 5-27). A criação do Instituto Histórico articulava-se a um projeto ideológico mais geral, possibilitando o estabelecimento de uma identidade nacional brasileira, processo no qual os intelectuais do IHGB procurariam unificar as múltiplas interpretações sobre o Brasil então existentes.

Deste modo, a criação do IHGB relacionou-se à construção da identidade nacional. As sessões da entidade sediada na Corte aconteciam aos domingos, quando seus membros debatiam assuntos previamente selecionados.

A identidade nacional forjada pelo IHGB enfatizava aspectos de continuidade em relação à Coroa portuguesa, entendida como o elemento civilizador nos trópicos (GUIMARÃES, 1988: 5-27). Com isto, a monarquia brasileira podia assumir-se como herdeira do projeto colonizador português, o que auxiliava, concretamente, na aceitação, pelos demais países, do aspecto nacional presente no incipiente Estado brasileiro. Neste 
sentido, a análise de Manoel Guimarães converge com àquela formulada por Eric Hobsbawm, qual seja: um dos fatores que possibilitaria a uma comunidade adquirir o estatuto de nacionalidade consistiria em "sua associação histórica com um Estado existente ou com um Estado de passado recente e razoavelmente durável” (1991: 49).

A elaboração da identidade nacional, por parte do IHGB, demarcava, em um duplo movimento, a alteridade, quer em âmbito interno (o escravo), quer no cenário internacional latino-americano (a república), fixando alguns traços marcantes para a autoinstituição desta sociedade brasileira, que se pretendia civilizada, europeia e excludente, pois, se por um lado enfatizava a herança portuguesa, por outro refutaria as contribuições dos demais grupos étnicos. Assim, o objetivo do Instituto Histórico seria estabelecer a nação como elemento central da produção artística brasileira, sem, contudo, romper com os padrões culturais herdados por esses intelectuais ao longo de sua trajetória. (GUIMARÃES, 1988).

A elaboração e a sistematização desse passado comum couberam ao IHGB, criado por personagens representativos da elite (política, econômica e cultural) que viviam no Município Neutro em 1838, época extremamente conturbada, onde a integridade territorial brasileira encontrava-se sob evidente ameaça (SCHWARCZ, 1998).

De fato, seus integrantes selecionavam-se não necessariamente entre aqueles portadores de notáveis atributos intelectuais, mas através de convite a indivíduos específicos, o que lhes forneceu identidade similar às "sociedades de corte" (SCHWARCZ, 1993: 100). Sob tal constituição, o conhecimento produzido pelo IHGB deveria pautar-se pela chancela oficial, legitimando, através desta interpretação específica, as relações de poder que caracterizaram a sociedade brasileira sob o Império.

Podemos inferir que a historiografia produzida pelo IHGB se articulava com as ações do Estado, visto que o Instituto sobrevivia, majoritariamente, devido às verbas originárias desta entidade, ${ }^{1}$ desfrutando de íntima relação com D. Pedro II, que participaria assiduamente de suas reuniões, desde a década de 1840 até seu banimento, no alvorecer do Governo Provisório republicano, em novembro de 1889. ${ }^{2}$ "As marcas de

\footnotetext{
${ }^{1}$ Segundo Lília M. Schwarcz, 75\% do orçamento do IHGB originava-se dos cofres estatais (1998: 127). O mesmo percentual é apresentado também por Manoel Guimarães. Igualmente, o então presidente interino do IHGB, Joaquim Manuel de Macedo, assinalava, em 1876, tal dependência dos cofres estatais, afirmando: "Desenha-se risonha, e reputar-se deve segura em seus modestos limites, a situação financeira do Instituto, graças ao favor e auxílio do poder legislativo" (1876: 470).

${ }^{2}$ De acordo com Lília Schwarcz, D. Pedro II presidiu 506 sessões do Instituto, entre 1840 e 1889 (1993: 102). À guisa de comparação, ocorreram 520 sessões do IHGB no período, de acordo com Francisco Iglesias (1988: 59-64).
} 
um saber oficial vão estar portanto bastante presentes, a despeito da definição formal do IHGB enquanto "estabelecimento científico-cultural"” (SCHWARCZ, 1993: 102). O IHGB arregimentou, ainda, os principais expoentes do movimento romântico brasileiro, o qual, sob a proteção do Imperador, intentava forjar uma cultural brasileira autônoma (SCHWARCZ, 1998: 126).

Neste sentido, a instituição reforçou o projeto centralizador da monarquia brasileira, auxiliando, dessa maneira, na invenção do Brasil como realidade efetiva (política e cultural). A contribuição do Instituto Histórico à centralização pode ser vislumbrada através de sua função sistematizadora das inúmeras narrativas geradas pelos seus congêneres regionais, os quais, a partir desse manancial de informações, produziriam seus relatos, transformados em narrativa oficial, de maneira a agregar as diferentes províncias em uma totalidade orgânica.

O apoio estatal revelava-se fundamental para a atuação (e mesmo a sobrevivência) do Instituto: além do financiamento às tarefas ordinárias, os cofres do Estado brasileiro também auxiliavam seus integrantes em sua incansável busca por fontes documentais. $\mathrm{Na}$ construção da memória nacional, o Instituto patrocinou pesquisas tanto no interior do Brasil como na Europa, onde uma plêiade de diplomatas-pesquisadores (como, por exemplo, Francisco Adolfo de Varnhagen, Antonio Gonçalves Dias e João Caetano da Silva) investigava, nos arquivos europeus, documentos que pudessem ser utilizados pelo Império na defesa das fronteiras do país, de modo a estabelecê-las em um momento de redefinição do mapa político sul-americano.

A organização do Instituto Histórico ocorreu sob os auspícios de D. Pedro de Alcântara, que lhe outorgou sua primeira sede efetiva (uma das dependências do Paço da Cidade), onde, doravante, ocorreriam suas sessões. Durante o período monárquico, o IHGB passou por quatro sedes: a primeira, quando de sua criação, nas dependências do prédio que então abrigava o Museu Nacional, logo após se transferindo para o Paço da Cidade, de onde migrou do térreo para o andar superior. No final da década de 1840, o Instituto recebeu parcela do " 3 " andar do antigo Convento do Carmo, contíguo à Capela Imperial, terminando por ocupar toda a sua área" (TAVARES, 1988: 44).

Outra forma de apoio oficial provinha dos prêmios outorgados por Sua Majestade, assim como através da realização de concursos que auxiliariam na elaboração da interpretação oficial da história nacional. De acordo com o general Aurélio de Lyra Tavares, D. Pedro II estabeleceu "três prêmios anuais a serem conferidos aos melhores estudos elaborados para disputá-los" (TAVARES, 1988: 43). Praticamente desde o seu 
nascedouro, o IHGB dependeria do Estado. Seus integrantes deveriam instituir a história nacional, mediante a fabricação da interpretação canônica a respeito do passado brasileiro, que enfatizaria efemérides e atos realizados por indivíduos, a partir de então, equiparados a heróis. A obra que analisaremos mais à frente, O Ano biográfico brasileiro, de Joaquim Manuel de Macedo, constitui-se um dos exemplos desta fabricação do passado.

Semelhante produção intelectual pretendia forjar a memória nacional, instituindo uma identidade ao nascente Estado brasileiro. Em consonância a este objetivo, realizouse a edição da Revista do Instituto Histórico e Geográfico Brasileiro (RIHGB), que participava, também, do esforço edificador do passado nacional, divulgando aqueles acontecimentos e vultos patrióticos dignos de recordação pela posteridade. Relacionado a este processo, a primeira geração de autores românticos, ${ }^{3}$ assim como Francisco Adolfo de Varnhagen, cada qual ao seu modo e apesar das divergências, participaram da construção da perspectiva oficial sobre o passado brasileiro, adquirindo papel de destaque e auxiliando na coleta, crítica e divulgação das fontes históricas que permitiriam a produção da História do Brasil.

Ao mesmo tempo, a história produzida nos quadros do Instituto Histórico, durante o século XIX, identificava no Estado o seu objeto máximo, ao passo que os ocupantes das funções públicas de maior destaque transformavam-se nos agentes privilegiados em tal narrativa. Constituía-se em responsabilidade do IHGB, em consonância com a criação da história pátria, estabelecer o culto cívico aos "pais fundadores" e encontrar as continuidades históricas, naquele momento bastante delicado para a vida nacional.

De acordo com Francisco Iglesias, a criação do IHGB foi contemporânea ao esforço de sistematização do passado empreendida por intelectuais de diversos países europeus. Neste processo, a história tornou-se uma disciplina científica, fundamentada em "fontes e documentos severamente recolhidos e tratados" (IGLESIAS, 1988: 60), que se pretendia portadora dos atributos da cientificidade tal como entendia o século XIX, quais sejam: a objetividade, a neutralidade e a comprovação empírica (no caso da história, através da documentação coletada). Elaboravam-se, neste momento, as grandes coleções de fontes documentais que, inspiradas na Monumenta Germaniae Historica, tinham na Revista do IHGB o seu equivalente nos trópicos (IGLESIAS, 1988: 62).

\footnotetext{
${ }^{3}$ Domingos José Gonçalves de Magalhães, Manuel de Araújo Porto Alegre, Joaquim Norberto de Sousa Silva, Joaquim Manuel de Macedo e Gonçalves Dias.
} 
Manoel Guimarães também associou a criação do IHGB à implantação, nos trópicos, de um modelo europeu de interpretação da história, onde tal disciplina pretenderia ensinar aos homens não só a evitar erros do passado, mas, principalmente, indicaria a direção mais adequada para os governantes seguirem.

Com a história é possível aprender de forma a não se comprometer a marcha do progresso social, História vista segundo sua instrumentalidade para a compreensão do presente e encaminhamento do futuro, princípios tão caros também àqueles que no Brasil se lançaram à tarefa de escrever uma história nacional (GUIMARÃES, 1988: 13).

A história aparecia, sob tal perspectiva, como um conhecimento eminentemente prático, não se limitando a análises teóricas. A narrativa originada do Instituto Histórico revelava-se extremamente pragmática, elucidando questões vinculadas ao poder estatal e legitimando as ações do Estado e da Família Real, assim como pretendendo provar a existência do Brasil desde o final do século XV. Acrescente-se, ademais, que tal narrativa fixava os modelos que deveriam pautar a vida das futuras gerações, através do conhecimento das ações dos grandes homens. Ou seja, a história constituía-se em mestra da vida, capaz de descortinar, àqueles que se dedicassem ao ofício de historiador, os felizes desígnios reservados ao Segundo Reinado.

Segundo Iglesias, a intelectualidade do IHGB apresentava, como características primordiais, a perspectiva pragmática em relação à história e a preocupação com a utilização de fontes históricas na confecção de sua narrativa. Por meio da história, em especial o estudo biográfico, haveria a preocupação em ensinar às novas gerações, fazendo com que os jovens aprendessem com aqueles que vieram antes. Este aspecto encontrava-se no primeiro número da Revista, na transcrição do discurso proferido pelo então secretário perpétuo do Instituto, o cônego Januário da Cunha Barbosa:

Deve ser a nossa associação, encarregada, como em outras nações, de eternizar pela história os fatos memoráveis da pátria, salvando-os da voragem dos tempos, e desembaraçando-os das espessas nuvens que não poucas vezes lhes aglomera a parcialidade, o espírito de partidos e até mesmo a ignorância [...] Nós vamos salvar da indigna obscuridade, em que jaziam até hoje, muitas memórias da pátria, e os nomes dos seus melhores filhos, nós vamos assinalar, com possível exatidão, o assento de suas cidades e vilas mais notáveis, a 
corrente de seus caudalosos rios, a área de seus campos, a direção de suas serras e a capacidade de seus inumeráveis portos (BARBOSA, 1839: 9-10).

O Instituto deveria, portanto, assumir uma vocação realista, auxiliando o Brasil não apenas a inventar seu próprio passado, mas, especialmente, a conhecer o território e a desenvolver a economia nacional.

A história nacional produzida no âmbito do IHGB sofreu influência do projeto formulado por Karl Friedrich von Martius e que evidenciava qual o papel desempenhado pelo Brasil no cenário internacional da época, que seria o de "realizar a ideia da mescla das três raças" (GUIMARÃES, 1988: 18) e, com isso, justificar as relações sociais presentes no território brasileiro, as quais possuíam como características básicas a exclusão e a violência associadas à exploração do trabalho escravo. A tese formulada por Von Martius assinalava a cada um dos grupos étnicos valores específicos, onde o elemento europeu portaria a civilização e o indígena poderia tornar-se civilizado, ao passo que o elemento africano inviabilizaria a transformação do Brasil em uma nação civilizada.

De fato, a adaptação dessa proposta pela intelectualidade ligada ao IHGB produziu uma narrativa que se pautava na construção da nacionalidade, através da fabricação de uma interpretação unívoca sobre o passado brasileiro e, devido ao seu aspecto teleológico, assinalaria a trajetória ideal do país. Isto não significava, entretanto, que a produção historiográfica do Instituto tenha obliterado algumas minorias (indígenas e alguns negros), desde que se pudesse salientar sua lealdade ao Estado - quer no período colonial, quer após 1822 (GUIMARÃES, 1995: 134-135).

A partir de então, uma delimitação estrita vigorará no IHGB. Enquanto sobre os negros recaía a pesada carga da impossibilidade de adaptação, em relação aos índios imperava a visão romântica - não menos teórica em sua idealização - que lhes reservava um espaço sobretudo exemplar (SCHWARCZ, 1993: 113).

Naturalizava-se, desse modo, a existência do Brasil, tornado realidade efetiva a partir do desembarque lusitano no atual litoral baiano, em 1500, ou mesmo antes, quando os índios se transformaram nos primeiros habitantes do Brasil. Em tal narrativa, por exemplo, durante o período colonial, enfatizar-se-iam o governo geral e a transformação do Brasil em vice-reino, em detrimento do sistema de capitanias hereditárias e da divisão 
em governos do Norte e do Sul. De modo análogo, os movimentos insurrecionais, assim como as rebeliões de escravos, tornar-se-iam estigmatizadas, pois ameaçariam a trajetória brasileira e indicariam a ruptura com a civilização europeia. ${ }^{4}$

Simultaneamente à invenção do passado, os letrados do IHGB procuraram, ainda, estabelecer uma cultura fundamentada em bases nacionais, de modo a consolidar a unidade nacional. “O indianismo chega também à iconografia política e vai fazer parte da representação do poder imperial e das cerimônias oficiais. Nas imagens da época, ele deixa de ser apenas um modelo estético para se incorporar à própria representação da realeza" (SCHWARCZ, 1998: 142). Neste sentido, a idealização do índio nos moldes do "bom selvagem", de Rousseau, e o esquecimento do negro poderiam fornecer alguma identidade coletiva ao Império: a monarquia, com um governante de nítida origem europeia, se autoinstituía com exóticas roupagens tropicais.

Em articulação ao discurso nacionalista de sua época, a RIHGB dedicou significativo espaço à temática indígena, com o objetivo de encontrar os primórdios do Brasil e a especificidade brasileira diante dos demais Estados nacionais. De acordo com Manoel Guimarães, poderiam ser percebidas três perspectivas distintas a respeito do índio: sua integração, a primazia concedida à educação e ao comércio para o diálogo entre o Estado e as comunidades indígenas, ou, ainda, a preponderância do poder estatal na execução de uma política indigenista (1988: 25).

Além do desejo de fundar uma historiografia nacional e original, há a intenção de não só ensinar e divulgar conhecimentos, como formular uma história que, a e exemplo dos demais modelos europeus, se dedicasse à exaltação e glória da pátria $[. .$.$] Tratava-se de construir uma vida intelectual em sua totalidade$ (SCHWARCZ, 1993: 102-104).

O Instituto Histórico se colocava objetivos bastante amplos, havendo a necessidade, além de se estabelecer o passado brasileiro, também de se difundi-lo ao maior público possível, de forma a moldar nação, amalgamando-lhe os "átomos". Além disso, o Instituto desejava o enaltecimento do Brasil e de seus governantes. O IHGB, herdeiro em terras tropicais de determinada leitura da Ilustração, teria função pedagógica e, como tal, procurou construir o passado do Brasil, não enquanto História, mas memória,

\footnotetext{
${ }^{4}$ Ver, a título de ilustração, a obra História do Brasil (1854) e História da Independência (1916), de Francisco Adolfo de Varnhagen.
} 
através de lembranças e esquecimentos (GUIMARÃES, 1995). Com isto, a construção do passado teve, por norma, evitar temas contemporâneos aos fundadores e que fossem julgados polêmicos, especialmente quando os protagonistas ainda habitassem o mundo dos vivos, evitando-se atritos desnecessários.

Ao que tudo indica, nossos acadêmicos [...] optaram por deixar que a poeira baixasse e os ânimos serenassem. Enfim, que o Império se aprumasse. Para, então, começarem a pensar em redigir a sua História. Entrementes [...] o Instituto iria sedimentando o terreno. Tecendo a Memória de um país recém separado da metrópole, carente de unidade e que dava seus primeiros passos [...] Tendo de enfrentar o peso de um passado colonial desagregador (GUIMARÃES, 1995: 119).

A construção da memória nacional, portanto, revelou-se uma ação muito mais política, e não apenas acadêmica. Ao ter por fio condutor a política, procedeu-se uma seleção a respeito de quais assuntos mereceriam divulgação durante aqueles anos turbulentos, arquivando-se os documentos potencialmente danosos à reputação de alguns integrantes da sociedade imperial, além de se promover a censura de "obras que apresentassem versões de episódios históricos incompatíveis com o projeto político em curso" (GUIMARÃES, 1995: 121).

Segundo Lúcia Maria Paschoal Guimarães, a construção da memória nacional e a consolidação do Império constituir-se-iam em processos correlatos, evitando-se deliberadamente o período situado entre a Revolução Pernambucana (1817) e a inauguração do IHGB, assim, priorizando-se o passado mais remoto, capaz de auxiliar na autoimagem que se pretendia estabelecer do presente (GUIMARÃES, 1995: 122-126)

O pressuposto básico desta construção seria ressaltar as continuidades entre Brasil e Portugal (elevado à figura de mãe-pátria), percebendo a colônia enquanto a origem do Império, com a Coroa portuguesa legitimando a casa reinante no Brasil. Optou-se por obliterar as fraturas, as rupturas, fossem na colônia (as revoltas coloniais), fossem durante a instauração da ordem monárquica (o processo de independência e a revolta de 1817, por exemplo), ou, ainda, no próprio tempo imediatamente anterior (1817-38). Deviam-se esquecer as dificuldades e começar-se novamente, a partir dos eventos que, em maior ou menor nível, unificavam a elite monárquica. Haveria, portanto, um lapso temporal, situado, grosso modo, entre 1817 e 1840. 
Em consonância com o projeto de Memória desenvolvido, nada foi impresso que pudesse evidenciar quaisquer indícios de contestação ao sistema colonial. A publicidade que a Revista [do IHGB] deu à documentação do passado remoto [entre 1500 e 1816] do Império trazia as marcas da continuidade, da centralização e da legitimidade (GUIMARÃES, 1995: 132).

As práticas comemorativas do IHGB realizavam-se por intermédio da Revista, assim como através da confecção de vestimentas, músicas, medalhas e imagens. "Lembrar para comemorar, documentar para bem festejar" (SCHWARCZ, 1993: 104). Cunhavam-se objetos com o intuito de não permitir o desaparecimento do passado brasileiro.

O Instituto jamais se propôs a se constituir como uma instituição democrática. Existiriam 4 modalidades distintas de associados, cada qual com atribuições peculiares: efetivos, correspondentes, honorários e beneméritos. Ressalte-se, outrossim, que a direção formal - isto é, a presidência honorária - restringir-se-ia ao dirigente máximo do Brasil ou aos seus congêneres de outros países. Os sócios efetivos deveriam residir na Corte e possuir obra acadêmica relevante, enquanto os correspondentes poderiam optar entre a produção acadêmica ou a doação de algum objeto de valor. Já os sócios honorários deveriam conciliar notório conhecimento à idade avançada, ao passo que os sócios beneméritos deveriam doar objeto de elevado valor financeiro, ou, ainda, terem realizado atividades meritórias. Essa distinção ocorreria, de acordo com Manoel Guimarães, apenas a partir de 1851, quando os novos estatutos do IHGB fixaram modalidades distintas de associação, além de determinarem o fim da vitaliciedade para os cargos de presidente e primeiro secretário. A partir desta data, o candidato a sócio devia comprovar alguma produção acadêmica, o que não significa que se desconsiderasse a "teia das relações sociais" (GUIMARÃES, 1988: 10), mas agora, formalmente, os candidatos deveriam comprovar atributos intelectuais.

Enquanto a posição de presidente honorário era cativa do imperador, a de presidente era exclusivamente ocupada por políticos renomados. Por sua vez, os sócios que adentravam o instituto por méritos acadêmicos ocupavam majoritariamente postos de secretários e oradores. Cabe notar ainda que, enquanto os presidentes cumpriam funções basicamente figurativas - abrindo seções ou lendo atas previamente elaboradas -, aos secretários cabiam papéis bem mais trabalhosos (SCHWARCZ, 1993: 105). 
A hierarquização interna ao IHGB reservava aos ocupantes de funções estatais o principal cargo de direção, qual seja o de presidente efetivo, que, durante o Império, permaneceu restrita aos mais proeminentes representantes da sociedade brasileira até 1889, pois ele "apresenta e representa o instituto [...] estabelece vínculos entre a associação e as grandes diretrizes da política oficial" (SCHWARCZ, 1993: 105). Assim, todos ocuparam cargos de dirigente do Estado imperial, e muitos receberam títulos nobiliárquicos em função dos serviços prestados à manutenção da ordem monárquica. ${ }^{5}$

Por outro lado, os secretários eram recrutados entre os intelectuais que compunham a agremiação carioca e, na prática, dirigiam as atividades acadêmicas do Instituto. Eles, muitas vezes, originavam-se do Colégio Pedro II, onde se dedicavam ao ensino e à preservação do passado, como, por exemplo, Joaquim Manuel de Macedo (SACRAMENTO BLAKE, 1970, v.4: 183). Segundo Lília Schwarcz, competia ao secretário "a labuta de quem acredita e pretende sustentar uma instituição cuja viabilidade é ainda incerta, e a imagem de um intelectual que fez da exaltação do próprio grupo a sua atividade intelectual fundamental" (1993: 106).

A função de orador também se restringiu aos sócios efetivos, e seu perfil assemelhava-se ao de secretário: intelectuais, que fizeram do IHGB uma atividade relevante em suas próprias biografias. Tal como o secretário, o orador responsabilizavase pelas atividades administrativas inerentes ao Instituto e, por isso, ambos desfrutariam de prestígio social, utilizado para impulsionar o IHGB, ao mesmo tempo em que auxiliava na elaboração da história do Brasil.

Os dirigentes do Instituto participaram da criação de uma história pátria, transformando-o em "um estabelecimento voltado para uma produção unificadora e estreitamente vinculada à interpretação oficial, fosse ela qual fosse" (SCHWARCZ, 1993: 108). A partir de então, o IHGB passou a ser, durante décadas, o centro produtor da interpretação canônica a respeito do passado brasileiro.

A partir de 1855, os fundadores do IHGB foram morrendo, e, em uma década, quase todos já haviam desaparecido, encerrando, gradualmente, a etapa da confecção da memória nacional, ao mesmo tempo em que se consolidava a unidade nacional (GUIMARÃES, 1995). Deste momento em diante, o Instituto Histórico poderia

\footnotetext{
${ }^{5}$ Presidiram o IHGB, de sua fundação até a proclamação da república (1889): José Feliciano Fernandes Pinheiro (Visconde de São Leopoldo, 1838-47), Cândido José de Araújo Viana (Marquês de Sapucaí, 184775), Luiz Pedreira do Couto Ferraz (1875-86) e Joaquim Norberto de Sousa Silva (1886-91) (INSTITUTO, s.d.).
} 
estabelecer sua interpretação sobre o passado brasileiro. Desde então, com a renovação do corpo social, os acontecimentos do passado recente poderiam ser analisados:

Munidos de 'régua e compasso', isto é, com o elenco das lembranças devidamente ordenado, os novos frequentadores da 'Casa da Memória Nacional' começariam a escrever a História do Império... Sintomaticamente, à proporção que a geração dos fundadores desaparecia, o 'véu pudico' que encobria o passado imediato do Império começou a ser levantado [...] [fazendo se] presente nas publicações trimestrais do Instituto Histórico (GUIMARÃES, 1995: 272-273).

O final da década de 1840 assinalou a maior aproximação entre o IHGB e o Estado imperial, e através deste movimento os intelectuais passaram a atuar em benefício da centralização monárquica, mediante a edificação do que se tornaria a interpretação oficial sobre o passado brasileiro, frequentemente sob as vistas de D. Pedro II. Simultaneamente, o recrutamento adquiriu feição mais acadêmica, indicando maior preocupação com a produção intelectual realizada pelo Instituto Histórico. Ademais, a Revista do Instituto Histórico e Geográfico Brasileiro explicitou essas alterações, ampliando o espaço dedicado à escrita da história nacional, em detrimento da simples coleta de materiais, conforme lhe solicitara o próprio Imperador:

É de mister que não só reunais os trabalhos das gerações passadas (...) como também, pelos vossos próprios, torneis aquela a que pertenço digna realmente dos elogios da posteridade (...) recomendo ao vosso presidente que me informe sempre da marcha das comissões, assim como me apresente, quando lhe ordenar, uma lista, que espero será a geral, dos sócios que bem cumprem com os seus deveres. (ATA, 1849: 552).

O IHGB, doravante vinculado sobremaneira ao mecenas imperial, trilharia novos rumos, imortalizando seus integrantes e, em especial, o Imperador, basicamente através das páginas da Revista. De fato, a RIHGB explicitou a preocupação daqueles letrados com a erudição, através da coleta e divulgação de relevantes documentos a respeito do passado brasileiro. Ao longo de sua trajetória, a publicação manteve a mesma divisão interna, a qual assumiu a forma de um panorama com três faces distintas: a primeira parte compunha-se de artigos escritos pelos acadêmicos do Instituto, além de documentos 
coletados pelos mesmos, assim como das polêmicas em que se envolviam; enquanto a segunda era composta por biografias e a terceira consistia na publicação de atas e outros documentos internos ao IHGB.

O apoio oficial ao IHGB revelar-se-ia, no transcorrer das décadas, um instrumento de efeitos ambíguos, pois, se lhe auxiliou em todos os elementos concernentes à sobrevivência material e à atuação profissional de seus membros, também significou fornecer-lhe nítida coloração conservadora, "ligada ao poder e com acento por demais acadêmicos" (IGLESIAS, 1988: 62). Ressalte-se, porém, que até a instalação dos cursos de graduação em História, o IHGB constituiu-se um elemento modernizador da narrativa histórica em nosso país, rompendo com os cânones presentes desde a época colonial (IGLESIAS, 1988: 63).

Segundo Schwarcz, o material publicado pela RIHGB compunha-se, majoritariamente, de artigos sobre temas históricos (45\%), e, ao acrescentarmos as biografias (16\%), cerca de $60 \%$ dos textos publicados realizam o enaltecimento da monarquia e de seu grupo dirigente. Ao longo do Império, cerca de $40 \%$ dos textos abordou a época monárquica (1808-89, incluindo aqui o período joanino), mesmo percentual dedicado aos períodos colonial e pré-colonial (SCHWARCZ, 1993: 138-139). Simultaneamente, os temas produzidos pelo Instituto, até o advento da República, foram marcados pela primazia da história política de tipo tradicional, abrangendo cerca de $45 \%$ de toda a produção intelectual do período (SCHWARCZ, 1993: 139).

Por outro lado, segundo Lúcia Guimarães, grande parte da produção intelectual do IHGB foi constituída pelo resgate de pessoas e fatos dignos de memória, mas este rememorar foi relativo, visto que a $R I H G B$ enfatizou a publicação de documentos relativos ao governo colonial e à Companhia de Jesus (1995: 131). A ênfase em temas associados ao período anterior a 1808 indica, de acordo com Schwarcz, a busca pela construção da identidade nacional fundamentada em uma interpretação específica da herança colonial, mas que, paradoxalmente, naturalizava o processo nacional de independência (1993: 113-114). A partir do grito do Ipiranga, podia-se confeccionar uma cronologia da nação brasileira forjada pelo IHGB e "tendo como modelo uma história católica, patriótica, permeável a um discurso evolucionista e muito vinculada à política oficial” (SCHWARCZ, 1993: 117).

Com a fundação do IHGB pôde-se estabelecer a genealogia da própria nação, através de uma análise que articulou as diferentes regiões coloniais, agora organizadas em uma totalidade marcada pela racionalidade e pela coerência, destacando-se 
determinados indivíduos, eventos e espaços, transformados em elementos formadores da cultura e sociedade brasileiras.

No Brasil, em particular, esse processo [de invenção do passado] esteve ligado à ideia de fundamentar historicamente um projeto nacional. Tal projeto, porém, se resguardava em uma pretensa objetividade construída a partir de uma consciente seleção de episódios e vultos que encobria interesses imediatos, tão essenciais quanto as exigências mais propriamente intelectuais (SCHWARCZ, 1993: 134).

De modo similar aos seus congêneres europeus, o IHGB procurava dotar o nascente país de sua certidão de nascimento, definindo suas origens, seus cidadãos ilustres, suas efemérides primordiais, enfim, datas, acontecimentos e personagens inesquecíveis, cujo culto permitiria eternizar a trajetória brasileira no mutável contexto internacional do século XIX. O IHGB realizaria tais funções através de sua produção acadêmica, em especial através da confecção de biografias e da elaboração de textos que legitimassem a manutenção de um Brasil uno e indivisível, existente a partir da expedição de Pedro Álvares Cabral, constituindo a face intelectual da disputa política (e militar) que contrapunha a Corte aos movimentos que eclodiam em diversas províncias (SCHWARCZ, 1993: 135). Estabelecia-se, desta maneira, uma análise historiográfica linear, permeada de certezas, com finalidades nacionalistas e, portanto, uniformizadora em sua perspectiva eurocêntrica e pouco afeita à crítica ao poder estatal.

\section{Joaquim Manuel de Macedo, ou a trajetória de um historiador e professor do século XIX}

É neste contexto que se insere a trajetória de Joaquim Manoel de Macedo. Nosso autor nasceu em Itaboraí, em 24 de junho de 1820, e morreu em 11 de abril de 1882. Formado em medicina pela faculdade do Rio de Janeiro, não exerceu a profissão, obtendo, como outros letrados de sua época, um emprego público. Tornou-se professor do Colégio Pedro II, no final da década de 1840, e "passou para a cadeira de Geografia e História Moderna e Média, lecionando também História do Brasil por ausência do $\mathrm{n}^{\mathbf{0}} 38$ (referindo-se ao professor Gonçalves Dias) desde 1851”(SANTOS, 2009: 75-76). 
Integrou o Conselho Diretor da Instrução Pública da Corte, assim como os quadros do IHGB. Participou de sua diretoria, a partir de 1852, atuando como orador e secretário do Instituto Histórico, chegando, inclusive, a exercer interinamente a presidência do grêmio, em 1876; foi sócio da Sociedade Auxiliadora da Indústria Nacional, e de outras; comendador das ordens da Rosa e de Cristo.

Foi um dos brasileiros que mais enriqueceram as letras pátrias e como romancista, dramaturgo, poeta e historiógrafo, seu nome ressoava e era aplaudido em todo o império, no primeiro gênero principalmente, porque ele foi o fundador do romance brasileiro, sendo ainda estudante, quando publicou a 'Moreninha' (SACRAMENTO BLAKE, 1970: 183-184).

Além de acadêmico e professor do Colégio Pedro II, participou da vida políticopartidária do Segundo Reinado, obtendo mandato de deputado provincial várias vezes e deputado geral (1864-68, 1878-81), teve o seu nome colocado em uma lista para senador do Império, mas jamais ocupou cargo executivo.

Macedo demonstrou grande fidelidade ao Imperador, a quem dedicou o Ano Biográfico Brasileiro. Em seu discurso como presidente interino do Instituto Histórico, afirmou:

À presente sessão solene e aniversária falta, como faltou às nossas sessões ordinárias d'este ano, a augusta presença; [...] o fraternal concurso de S. M. o Imperador, desde março ausente do Império; ao partir, porém, (em viagem) de coração e de inteligência, o Sr. D. Pedro II deixou nos suavíssima consolação e instante recomendação de solicitudes. [...] A recomendação instante, dez vezes reiterada, insistente na despedida: Cuidem do nosso Instituto Histórico nós temos a consciência de ativo zelo em procurar desempenhá-la, lembrando o imperial protetor, e cumprindo o nosso dever em todo caso de generoso tributo de patriotismo. [...] V. A. Imperial [a princesa Isabel] exprime, exalta e sublima n'esta assembleia dois sentimentos transbordantes do coração de brasileira e do coração de filha: o amor da pátria e a saudade do pai: o amor da pátria, que honorifica a sociedade cultivadora da história do Brasil; a saudade do augusto pai, a lembrar aquele que hoje sem dúvida está lembrando se do Instituto (MACEDO, 1876a: 467-470). 
A lembrança das ações individuais funcionaria, em seu discurso, como um antídoto ao esquecimento que a posteridade poderia relegar a tais personagens; função de um historiógrafo, que buscou assegurar-lhes um lugar destacado na lembrança de seus concidadãos, contemporâneos e futuros.

Escreveu diversas obras, entre romances, peças de teatro e textos de propaganda política, além de livros para o ensino de história, destacando-se entre estes últimos, Lições de história do Brasil para uso dos alunos do imperial colégio de Pedro II (1861, 1863), Lições de história do Brasil para uso das escolas de instrução primária (1865) e Mulheres célebres (obra adotada pelo governo imperial para as escolas primárias femininas da Corte, 1878). Publicou, ainda, os seguintes livros, cujo assunto foi o passado do Brasil monárquico: O Ano biográfico brasileiro (1876); Suplemento ao ano biográfico brasileiro (tratando do primeiro quadrimestre do ano, 1880); e Efeméride da história do Brasil (1877), além de diversos textos na RIHGB.

Assim, em sua atuação profissional, Macedo não se limitou ao espaço da sala de aula, produzindo textos (eruditos ou didáticos) que ajudavam na construção do Estado Imperial. É importante frisar que tais ações aconteciam praticamente em paralelo: moldar as mentes de muitos dos futuros dirigentes brasileiros e escrever a História desse jovem Estado, que se pretendia europeu e civilizado, inserido nos trópicos.

Torna-se nítida assim a distinção entre a pesquisa e o ensino de História, tendo cada atividade o seu local institucional: o IHGB e o ICPII [Imperial Colégio Pedro II], respectivamente. Ou dizendo de outra maneira, torna-se nítida a diferença entre escrever e difundir a História do Brasil. Uma distinção ou diferença, porém, que não eliminava o papel de ambas as atividades na fixação de uma memória (MATTOS, 1993: 98).

O professor e intelectual erudito procurava, desta maneira, consolidar uma visão específica sobre o passado brasileiro. Atuava em esferas distintas, mas mantendo um objetivo único. 


\section{A caravana dos heróis em marcha: $O$ ano biográfico brasileiro, de Joaquim}

\section{Manuel Macedo}

A obra em questão, $O$ ano biográfico brasileiro, constituiu-se numa tentativa de demonstrar, para o público estrangeiro, o que seria a História do Brasil, redigida a partir de biografias de pessoas ilustres. Foi "escrito [por Macedo] a convite da ilustrada Comissão Superior da Exposição Nacional de 1875 com o fim de aparecer na Exposição de Filadélfia" (MACEDO, 1876: folha de rosto). Percebe-se, portanto, o caráter oficial do livro, produzido com a intencionalidade de explicitar a trajetória brasileira no cenário internacional. Com efeito, tal obra elaborou um "uso particular do biográfico, qual seja: os retratos em papel e letras ali urdidos deveriam compor o mosaico que bem apresentasse os brasileiros perante os outros, em particular, os que também partilhavam em alguma medida, a identidade de americanos" (GONÇALVES, 2011: 453).

A Exposição de Filadélfia, realizada em 1876, foi um acontecimento internacional que, tendo por objetivo a comemoração da independência dos Estados Unidos, possibilitou que cada Estado soberano demonstrasse o que acreditava ter de mais relevante de si para expor ao mundo, procurando, cada qual, expor seus avanços científicos e tecnológicos e sua inserção na (e como representante da) civilização. Cabe sublinhar que as exposições mundiais foram as "grandes celebrações internacionais do progresso" (HOBSBAWM, 1988: 54).

No Brasil, a notícia da Exposição de Filadélfia produziu grande alvoroço D. Pedro II, inclusive, foi aos Estados Unidos, tendo visitado a exposição. Ela mobilizou mobilizados intelectuais de diversas províncias (além da Corte), reunidos com o objetivo de construir a melhor imagem possível do único Império existente nas Américas.

Ao Império do Brasil era essencial não ser exibido como "exótico", mas, ao contrário, como um baluarte avançado da civilização nos trópicos. Neste sentido, o governo imperial enviou uma comitiva para acompanhar os preparativos da Exposição, sendo um de seus objetivos produzir uma imagem "simpática" do Império.

O livro O Ano Biográfico Brasileiro compreende 365 biografias, organizadas pelos dias do ano e, em geral, homenageando um indivíduo ou acontecimento. Assim, a cada biografia corresponde uma data. É importante frisar que o livro se destinava a um público estrangeiro que, em geral, desconhecia a realidade e a história do Brasil. 
Conforme nos recorda Márcia de Almeida Gonçalves, o gênero biográfico assumiu importância no século XIX, ajudando a "contribuir para a caracterização de singularidades e especificidades da cultura de povos e sociedades [... [ a contribuir para a fundação simbólica de individualidades nacionais" (2011: 437, 439); em outras palavras, a biografia auxiliava a identificação de um país no cenário internacional, incorporando tal Estado ao rol das nações civilizadas. Desta maneira, no Brasil monárquico a intelectualidade associada ao IHGB procurou elaborar inúmeras biografias (GONÇALVES, 2011: 451-453), que, em seu conjunto, permitiriam construir a identidade nacional, moldando uma visão do passado coletivo. Em alguma medida, a ênfase nas biografias aparecia já na inauguração do IHGB; segundo o Cônego Januário da Cunha Barbosa:

E será pouco arrancar do esquecimento, em que jazem sepultados, os nomes e feitos de tantos ilustres Brasileiros que honraram a pátria por suas letras e por seus diversos e brilhantes serviços? [...] Uma biografia dos mais preclaros Brasileiros é tarefa, mui superior às forças de um só homem [...] mas a glória que deve resultar de uma tal empresa [...] refletirá também sobre o nosso Instituto, porque são do seu grêmio os empreendedores da desejada biografia brasileira (1839: 14).

De fato, Macedo procurou realizar, na redação de $O$ Ano biográfico brasileiro, a biografia da nação proposta por um dos fundadores do IHGB, ajudando, desta maneira, a produzir um imaginário acerca da sociedade brasileira oitocentista.

Assim, Joaquim M. de Macedo pautou sua escrita portando-se muito mais como historiógrafo que como historiador, palavras distintas, com diverso significado no século XIX.

Ambos estes literatos escrevem a história, mas de diferente modo, e com diversas circunstâncias. O primeiro [historiógrafo] é um literato pensionado do Estado, ou de um príncipe para escrever a sua história, e corresponde quase sempre ao que se chamava cronista. O segundo [historiador] é um literato que compõe uma história sem ser pensionado, e quase sempre não contemporânea. O 'historiógrafo' é um simples analista, que refere acontecimentos, reúne matérias: o 'historiador' escolhe os, põem nos em ordem, examina os fatos, 
julga os homens e as cousas: costuma este ser menos adulador e mais imparcial que o 'historiógrafo' (SILVA, 1877, v. 2: 133).

Macedo pareceu-nos considerar-se historiador, e, no que se refere à colônia, foi juiz rigoroso, distribuindo loas e críticas, honras e demais méritos, por exemplo, com Bartolomeu Bueno da Silva (o Anhanguera):

É preciso julgar os homens conforme as ideias, os costumes, e a influência da civilização de sua época (...) seria perverso algoz em nosso tempo de hoje (...). Mas no século décimo sétimo Bueno da Silva fez em Goiás o que faria outro chefe sertanejo igual a ele em ousadia e bravura. (...) Perdoe a nossa civilização a cruel violência de Bueno da Silva (...) e honre-se a memória do romanesco Anhanguera (...) é um dos mais belos episódios da imensa epopeia dos sertanejos paulistas (MACEDO, 1876, v. 2: 295-296).

Para melhor compreender $O$ Ano biográfico brasileiro, estabeleci uma sintética tipologia, de modo a classificar as biografias, isto é, enfatizando o que elas buscavam relembrar. Assim, com relação às homenagens aos acontecimentos, eles parecem indicar "lugares de memória", sendo estes, na colônia, considerados as bases da civilização: a cultura e a administração colonial, com a primeira, muitas vezes, apoiada pelo Estado (exemplificada pela instalação da Academia dos Seletos e da Academia dos Esquecidos, durante o século XVIII); a segunda abrangia, além do Governo-Geral e do Vice-Reinado, também a defesa e conquista do território.

Macedo entendia a História como um modelo, a especialidade que evidenciava o exemplo a ser seguido: “O Homem que é elevado às maiores grandezas aos voos de sua inteligência ilustrada e pelo encontro de preclaras virtudes, fica na história como exemplo e farol" (MACEDO, 1876, v. 1: 165). Considerava-a, também, como a disciplina que estudava as civilizações desde os primórdios, pois "a marcha da civilização dos povos estuda-se desde o momento de seus primeiros, dúbios e temerosos passos, desde o ensaio das asas mal emplumadas da águia, que apenas sai do ninho, e ainda não pode elevar-se soberba acima dos Andes, e a procurar o sol” (MACEDO, 1876, v. 1: 138).

Mas a História, em Macedo, não se constitui apenas na narrativa objetiva, baseada em testemunhos fidedignos e racionais; desta forma, a História também recorreria a algumas lendas como explicação, ainda que, como intelectual oitocentista, demonstrasse incredulidade em seu aspecto factual. Assim, por exemplo, na biografia de Estácio de Sá 
( $1^{\text {o }}$ de junho), Macedo afirma que o próprio São Sebastião lutara ao lado dos portugueses e aliados indígenas, contra os franceses e as tribos que os apoiavam, em uma batalha travada sobre canoas.

Poéticas, embora inverossímeis, salvo sempre o poder miraculoso de Deus, que ninguém pode duvidar; mas que a nenhum homem é dado assegurar por autoridade própria, romanescas, enfeitadas com o maravilhoso, que encanta a imaginação, as tradições antigas e dos tempos primitivos são galas, tesouros ornamentais, flores preciosas da infância dos povos, e do berço das nações: é de dever como que egoísta, de gozo suave aceitá-las sem averiguá-las (MACEDO, 1876, v. 2: 340).

Neste sentido, pode-se observar que o autor escreveu um livro cuja grande preocupação foi a consolidação de uma memória de um Brasil católico, português e branco, a partir do qual o Império aparentava ser o herdeiro legítimo dessas tradições. Nesta obra, assim como realizou em Lições de História do Brasil, Macedo "fixa temas, sublinha valores, difunde crenças, ergue um panteão de heróis e marca datas" (MATTOS, 1993: 99), assinalando lembranças, mas, também, esquecimentos.

Selma Rinaldi Mattos indica a presença, nas Lições de História do Brasil (tanto "para uso dos alunos do Imperial Colégio de Pedro II" como "para uso das Escolas de Instrução Primária”), dos indivíduos destacados no conteúdo programático ensinado por Macedo: exploradores (Cristóvão Jacques, Martim Afonso de Souza), governadores (Tomé de Souza, Duarte Coelho), entre outros (1993: 107-108). Ora, em O ano biográfico brasileiro essa presença assumia um papel ainda mais importante, visto que o anuário se organizou estritamente através de biografias individuais (com apenas duas exceções, a biografia das "heroínas de Tejucupapo", fixada em 7 de dezembro; e as vidas de D. Manoela de Santa Clara e D. Rita do Sacramento, fixadas como uma só biografia e alocada em 22 de junho.

Outro aspecto importante que aproxima $O$ ano biográfico dos brasileiros com Lições de História do Brasil consiste na temática. Assim, entre os assuntos das biografias podemos encontrar, por exemplo, no que diz respeito ao período colonial, a ocupação e defesa do território pelos portugueses contra os indígenas, franceses e holandeses, é o caso das biografias de Vasco Fernandes Coutinho e Duarte Coelho Pereira, o qual "serviu à colonização e à civilização de Pernambuco imensamente mais do que todos os outros 
donatários" (MACEDO, 1876, v. 2: 437); além das biografias de Tomé de Souza, Mem de Sá, Gomes Freire de Andrade, Luiz de Vasconcellos e Souza, Martim Affonso de Souza e Estácio de Sá, assim como as de Jerônimo de Albuquerque (derrotou os indígenas em Pernambuco, no século XVI), de seu filho Jerônimo de Albuquerque Maranhão (conquistador do Rio Grande do Norte, no século XVII) e de Manoel de Moraes Navarro (destruidor de vários quilombos, no século XVIII).

Selma Rinaldi Mattos destacou, ainda, nas Lições de História do Brasil a temática da construção do Estado brasileiro através da independência (1993: 112, 132, 133). Semelhante tema apareceu em destaque em $O$ ano biográfico brasileiro por meio da biografia de Dom Pedro I, contemplado com 37 páginas (a mais volumosa de todas). De acordo com Macedo,

A 12 de Outubro do mesmo ano de 1822 D. Pedro foi no Rio de Janeiro solenemente proclamado 'Imperador Constitucional e Defensor Perpétuo do Brasil' [...] Perto de meio século já lá vai depois que desapareceu dentre os homens D. Pedro I, e a história imparcial e severa que registra seus erros, justa e devidamente honorificadora de sua memória o apresenta à posteridade com o esplendor de títulos tão grandiosos que obrigam a admiração (1876, v. 3: 216, 236).

Por fim, Macedo considerava $O$ ano biográfico brasileiro uma "galeria exclusivamente dedicada a brasileiros ilustres já finados” (MACEDO, 1876: 405). Retratados como heróis, tais biografados adaptavam-se à "construção de modelos de ação virtuosa, passíveis de repetição por parte daqueles que em tais exemplos se mirassem" (GONÇALVES, 2011: 457) e, como tal, podendo inspirar as ações de futuros indivíduos que neles se espelhassem; ao tratar, apenas, dos mortos, abordou-os (os biografados) em sua totalidade, pois considerou toda a vida destes, retendo, e, assim, por conseguinte, imortalizando os que considerava relevantes. Com isso, derrotava a morte, e, por ser um anuário, significava o eterno retorno, através dos atos de relembrar e, metaforicamente, reviver, mas, também, de esquecer.

Desta forma, Macedo imortalizou alguns indivíduos e suas ações, e isto nos remete a Hannah Arendt, quando a mesma afirmava que:

O que para nós é difícil perceber é que os grandes feitos e obras de que são capazes os mortais, e que constituem o tema da narrativa histórica, não são 
vistos como parte, quer de uma totalidade ou de um processo abrangente; ao contrário, a ênfase recai sempre em situações únicas e rasgos isolados. Essas situações únicas, feitos ou eventos, interrompem o movimento circular da vida biológica. O tema da História são essas interrupções - o extraordinário, em outras palavras. [...] No início da História Ocidental, a distinção entre a mortalidade dos homens e a imortalidade da natureza, entre as coisas feitas pelo homem e as coisas que existem por si mesmas, era o pressuposto tácito da Historiografia [...] se os mortais conseguissem dotar suas obras, feitos e palavras de alguma permanência, e impedir sua imperecibilidade, então essas coisas ao menos em certa medida entrariam no mundo da eternidade e aí estariam em casa, e os próprios mortais encontrariam seu lugar no cosmo, onde todas as coisas são imortais, exceto os homens. A capacidade humana para realizá-lo era a recordação, Mnemósine, considerada portanto como mãe de todas as demais musas [...] a consequência mais importante do domínio secular foi ter a crença na imortalidade individual [...] perdido sua força politicamente coercitiva. [...] Em outras palavras, a secularização da época moderna traz mais uma vez à cena aquela atividade que Aristóteles chamara de 'athanatídzein', um termo para o qual não temos equivalente imediato nas línguas vivas. O motivo por que menciono esta palavra é que ela aponta para uma atividade de 'imortalizar', mais que para o objeto que deve tornar-se imortal (ARENDT, 1988: 72, 104, 105).

Desta maneira, podemos sugerir que o ato de imortalizar, em $O$ ano biográfico brasileiro, transformava tais indivíduos em legítimos fundadores da sociedade imperial; cada um a seu modo, em suas diferentes áreas de atuação (religião, artes, administração estatal, guerras), desempenhou uma ação que contribuiu para a realização deste Brasil oitocentista; e, em função destas realizações, mereceriam a gratidão da posteridade, devendo suas vidas exemplares serem objeto de culto cívico por parte dos contemporâneos de Macedo.

\section{Fontes}

ATA da $212^{\text {a }}$ sessão em 15 de dezembro de 1849, honrada com a augusta presença de S.M. O Imperador. In: Revista do Instituto Histórico e Geográfico Brasileiro. Rio de Janeiro, 1849, t. XII, pp. 550-557. 
BARBOSA, Januário da Cunha. "Discurso recitado no ato de estatuir-se o Instituto Histórico e Geográfico Brasileiro, pelo secretário perpétuo cônego Januário da Cunha Barbosa". In: Revista do Instituto Histórico e Geográfico Brasileiro. Rio de Janeiro, 1839, t. I, pp.9-18.

MACEDO, Joaquim Manoel de (1876). O ano biográfico brasileiro, 3 v. Rio de Janeiro: Tip. e Lit. do Imperial Instituto Artístico.

(1876a). Discurso na Sessão Magna Aniversária do Instituto Histórico e Geográfico Brasileiro (como Presidente interino, em 1876). Revista do Instituto Histórico e Geográfico Brasileiro. Rio de Janeiro, 1876, t. 39, pp. 465-472.

SACRAMENTO BLAKE, Augusto Victorino Alves (1970). Diccionario Bibliographico Brasileiro. 2 ed. Rio de Janeiro: Imprensa Nacional, vol. 4, 1970.

SILVA, Antonio de Moraes (1858). Diccionario da Lingua Portugueza. 2 v., 6 ed. Lisboa: Tip. de A. J. da Rocha, 1858. (1877). Diccionario da Lingua Portugueza. 2 v., 7 ed. Lisboa: Tip. de J. G. de Souza Neves.

\section{Referências bibliográficas}

ARENDT, Hannah (1988). Entre o passado e o futuro. São Paulo: Perspectiva.

CASTORIADIS, Cornelius (1982). A instituição imaginária da sociedade. São Paulo, Paz e Terra.

GONÇALVES, Márcia de Almeida (2011). Histórias de gênios e heróis: indivíduo e nação no Romantismo brasileiro. In: GRINBERG, Keila; SALLES, Ricardo (Orgs.). O Brasil Imperial, volume II (1831-1870). 2a . ed. Rio de Janeiro: Civilização Brasileira, pp. 425-465.

GUIMARÃES, Lucia Maria Paschoal (1995). Debaixo da imediata proteção de sua majestade imperial. Rio de Janeiro, Instituto Histórico e Geográfico Brasileiro.

GUIMARÃES, Manoel Luís Salgado (1988). Nação e civilização nos trópicos: o Instituto Histórico e Geográfico Brasileiro e o projeto de uma história nacional. Estudos Históricos. Rio de Janeiro, n. 1, pp. 5-27.

HOBSBAWM, Eric J. (1988). A era dos impérios. Rio de Janeiro: Paz e Terra. (1991). Nações e nacionalismo desde 1780: programa, mito e realidade. São Paulo: Paz e Terra.

IGLESIAS, Francisco (1988). Há 150 anos fundava-se o Instituto Histórico e Geográfico Brasileiro. Revista do Instituto Histórico e Geográfico Brasileiro, Suplemento. Rio de Janeiro, pp. 59-64.

INSTITUTO HISTÓRICO E GEOGRÁFICO BRASILEIRO. O IHGB. Resenha Histórica, s. d. Disponível em: <http://www.ihgb.org.br/ihgb27.php>. Acesso em: 10 mar. 2015.

MATTOS, Selma Rinaldi de (1993). Brasil em lições: A história do ensino de história do Brasil no Império através dos manuais de Joaquim Manuel de Macedo. Dissertação (Mestrado em Educação). Fundação Getúlio Vargas, Rio de Janeiro.

SANTOS, Beatriz Boclin Marques dos. O currículo da disciplina escolar História no Colégio Pedro II - a década de 1970 - entre a tradição acadêmica e a tradição pedagógica: a História e os Estudos Sociais. Rio de Janeiro: Mauad, 2009.

SCHWARCZ, Lilia Moritz (1993). O espetáculo das raças: cientistas, instituições e a questão racial no Brasil (1870-1930). São Paulo, Companhia das Letras. 
(1998). As barbas do imperador: D. Pedro II, um monarca nos trópicos. São Paulo, Companhia das Letras.

TAPAJÓS, Vicente (1989). A Revista em três tempos. Revista do Instituto Histórico e Geográfico Brasileiro. Rio de Janeiro, vol. 150, n. 362, pp. 3-18, jan./mar.

TAVARES, Aurélio de Lyra (1988). O Sesquicentenário do Instituto. Revista do Instituto Histórico e Geográfico Brasileiro, Suplemento. Rio de Janeiro, pp.39-47.

Artigo recebido em 17 de fevereiro de 2015.

Aprovado em 15 de junho de 2015.

DOI: 10.12957/intellectus.2015.18799 